\title{
The Effect of Polyvinyl Acetate Polymer on Reducing Dust in Arid and Semiarid Areas
}

\author{
Gholamreza Tadayonfar ${ }^{1}$, Narges Shahmiri², Mohammad Hassan Bazoobandi ${ }^{3 *}$ \\ ${ }^{1}$ Department of Civil Engineering, University of Hakim Sabzevari, Sabzevar, Iran \\ ${ }^{2}$ Department of Environmental Management, Environmental Organization, Tehran, Iran \\ ${ }^{3}$ Faculty of Science, Shahid Sherafat, University of Farhangian, Tehran, Iran \\ Email: *m_bazoobandi@yahoo.com
}

Received 25 January 2016; accepted 18 March 2016; published 21 March 2016

Copyright (C) 2016 by authors and Scientific Research Publishing Inc.

This work is licensed under the Creative Commons Attribution International License (CC BY).

http://creativecommons.org/licenses/by/4.0/

(c) (i) Open Access

\begin{abstract}
Because the large areas of Iran are on arid and semiarid belt of the world, it has many problems due to windstorms. Wind storms cause dust and haze due to a mass of fine sand or silt soil elevated in the atmosphere. It makes heart disease-cardiovascular and respiratory and so is detrimental for the children. These have plagued the residents and so lives of them are disrupted every so often. In this research, the subject soil stabilization using adherence of poly vinyl acetate polymer as a way to reduce the production of dust is defined for prone area. In this paper, the effect of poly vinyl acetate polymer on silt soil has been studied. In this study the samples were uncompacted particles of soil with different amount of water-solvated polymer $(0,5,10,15,20,25,30$ grams per meter squared) poured over them. These samples are kept in experimental environment for 7 days. After ensuring complete dryness, their stabilities are tested against wind flow with $20 \mathrm{~m} / \mathrm{s}$ speed. Results showed that adding more polymers to soil would considerably increase its particles' stabilities. This stability is due to positive reaction of polymer with soil particles. The effect of this stability is maintained during sample drying time in the lab and the soil maintains its characteristics during testing. The best results are obtained for 20 grams polymer per meter squared, where caused an increase in stability to about 15 times that of the soil without polymer.
\end{abstract}

\section{Keywords}

Haze, Poly Vinyl Acetate Polymer, Arid and Semi-Arid Area, Stability against Wind

\section{Introduction}

The specific wind of arid and semi-arid areas that caused creating the dense cloud of dust to height about 3000

*Corresponding author.

How to cite this paper: Tadayonfar, G., Shahmiri, N. and Bazoobandi, M.H. (2016) The Effect of Polyvinyl Acetate Polymer on Reducing Dust in Arid and Semiarid Areas. Open Journal of Ecology, 6, 176-183.

http://dx.doi.org/10.4236/oje.2016.64018 
meters is called dust storm. The density of this dusty cloud (about 4000 ton dust per each cubic kilometers of air) is too much that could block the view completely [1]. Wind separates fine particles from the surface in three ways:

1) Suspend state covers the particles with diameter less than or equal 100 micron included $3 \%-38 \%$ of all cases.

2) Swirl moves the particles larger than 100 and smaller 500 micron in diameter included $55 \%-75 \%$ of all cases.

3) Rolling motion rotates the particles larger than 500 and smaller or equal 2000 micron in diameter. This covers $7 \%-25 \%$ of all cases.

But the World Meteorological Organization (WMO) provided following definitions to haze events that included removal of fine particles from the land surface [2]:

a) Dust storm as a result of turbulent flow and wind turbulence transmitted lots haze (mainly Silt and Clay) to air and the visibility reduced to less than 1000 meters.

b) Blowing dust occurred by wind blowing to a considerable height above ground and caused visibility reduction between 1 and 2 kilometers (without air turbulence).

c) Dust haze is created by the suspended haze. This haze separates from ground before dust storm occurrence.

d) Dust devils as a result of hurricane wander high columns of haze. Their height could reach to 300 meters or more.

\section{Dust Storms and Its Environmental Effects}

Identification of regimes tend to haze produce may determine using satellite data. Most of dust storms clearly are seen in limited areas. Global distribution of dust storm study provided ring of dust. These rings mainly extended in northern hemisphere from north of Africa to China and outside of this ring dust density is reduced. In fact dust creation could be typical respond to vegetation changes [3]. Dust usually impacts on the human activities and the environment such as cloud formation and properties and rainfall, visibility reduction, increasing temperature, degradation of air quality, diseases transmission, and breathing problems. Atmospheric dust prevents sunlight penetration and may cause decline in agriculture production to 5\% - 30\% [4]. Dust transmission in the atmosphere and entering them into sea cause logging toxic and heavy metals on the seas [5]. Also dusts may have microorganisms like bacteria and fungi or degradation organism resistance chemical compounds. They could cause disease by creating larvae and toxic compound [6]. Pterygium and sandy keratitis are among the common diseases caused by haze. Sand particles also may cause scratched cornea and reducing visibility [7].

\section{Dust Sources of Iran}

Dust storms blow in about 21\% area of Iran. The most important dust resources are from Syrian Desert, north of Arabian Peninsula desert and south of Iraq deserts that imported into the west Country. The number of stormy days only in Khuzestan is more than 15 days in a year [8]. Dry bed of Hamun Puzak is the most important solid particles of storms power supply in southeast of Iran. High temperature s during 120 days wind blowing and cassation of the rainfall and physical drought of the environment provided appropriate conditions to blowing dust storms [9]. The areas where are the rich Silt is responsible of the most haze storms because the adherence between the particles of Silt soil is low inherently also since no interlock between particles in result of relatively large rounded slid on each other and transmitted by water and wind. To avoid Silt motion and movement should increase friction and engagement between soil grains or adherence between the particles. Many factors included type of soil, topography, and climate could make a prone area for haze creation. Among these changing soil properties by additives considered a factor for controlling haze. Using adhesive materials like cement, lime, tar, yarn, and slag can solve weak point of these soils largely [10]. Cement and lime used for soil stabilization from many years ago. Tar jointed to stabilizers after oil exploration. Tensile strength is the main property of the yarn that resulted in increasing soil tensile strength. Root of plants as a yarn could cause significant increase in soil stabilization and consolidation [11]. Slag is a pozzolanic material that could use to soil stabilization [12] and [13]. Continuous spraying water on the soil bed is one of common approaches to avoid soil erosion however could be quick costly depending on the climate of design area and requirement labor [14]. From 1980 soil stabilization by polymer got more importance than old stabilizer because of simple implementation and high perform speed and creating high strength [15] and [16]. According to different features of these chemical materials they 
used with different goals and forms to increase holding capacity of the soil and controlling wind and water erosion [17]. Therefore in this study effect of Poly vinyl acetate polymer as stabilizer factor of haze studied.

\section{Materials and Methods}

In the conducted study soils of south areas of Sabzevar and Emulsion Poly vinyl acetate polymer had been used. It was done in soil mechanics laboratory and wind tunnel of Hakim university of Sabzevar.

\subsection{Soil}

The used soil in this experiment was Silt with low paste property $(\mathrm{Pl}=4)$ that explored from south areas of Sabzevar where aggregated eolian silts and has been simulated for this project. Relative density of this soil Gs = 2.7 and its bulk density is 1.54 grams $/ \mathrm{cm}^{3}$. The soil passes sieve No.200 and hydrometer test has been done for it. The results are drawn in Figure 1 in the gradation curve.

\subsection{Chemical Material}

Chemical substance in this study, used vinyl acetate polymer to modify silty soil with about $50 \%$ solids in water. Poly vinyl acetate is a material with free radical polymerization of vinyl acetate that obtain from source of monomer vinyl. This article discovered and was made first time by Fritz kalate in Germany in 1912. It is known in the trade and industry with PVAc as the chemical structure of monomers and specifications are given in Figure 2 and Table 1, respectively.

\section{Samples Preparation and Description of Test}

We knew that adding polymer to soil increase its adherence. Therefore we must can obtain this adherence. It obtained with soil mechanics laboratory tests. To start and preparation suspension the specific amount of polymer powder combined with 50\% weight of water. Provided suspension added to the silt soil with different

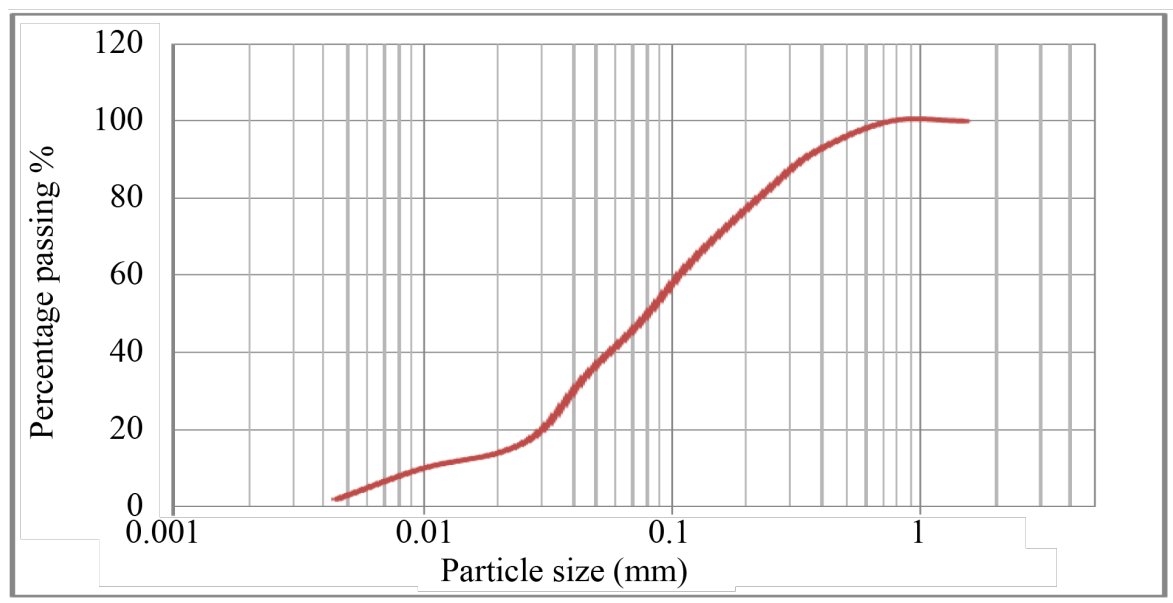

Figure 1. The gradation curve of used soil.

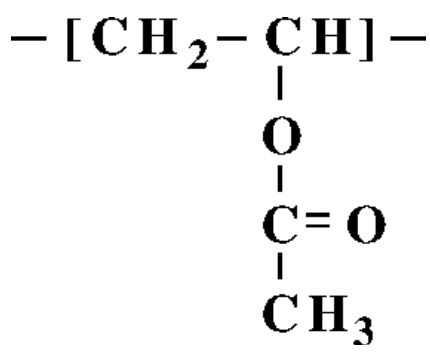

Figure 2. Chemical structure of used monomers in emulsion polymer. 
Table 1. Poly vinyl acetate polymer specifications.

\begin{tabular}{cc}
\hline Appearance & Milky fluid \\
\hline Density in $25^{\circ} \mathrm{C}$ & 1.19 \\
$\mathrm{pH}$ & $4-6$ \\
Viscosity (pas) & $150-200$ \\
Particles size (micron) & 0.160 \\
Minimum film formation temperature $\left({ }^{\circ} \mathrm{C}\right)$ & 150 \\
Elastic modulus (GPa) & $1.275-2.256$ \\
Tensile strength (MPa) & $29.4-49.0$ \\
Percentage of elongation to rupture in $20^{\circ} \mathrm{C}$ & $10 \%-20 \%$ \\
Glass transformation temperature & 30 \\
\hline
\end{tabular}

coefficients to achieve the best dose to the soil stabilization. The suspension concentrations started from without polymerto 30 grams polymer per square meter, with increasing 5 grams polymer/squared meter relative to last state.

\subsection{Proctor Compaction Test (ASTM D698-78)}

The mixed samples with different amount of suspension each time in 3 layers casted in the proctor cast (4 in diameters and height 4.6 in) to fill it and compressed by the 25 blow hammer with 2.5 kilograms weight. To determination of dry specific weight estimation of natural specific gravity and its moisture is required. To achieve maximum density (maximum dry specific weight) and most appropriate moisture percentage of the soil should repeat several times with different amount of water [15]. Although by this method looks consuming suspension became thinner and the polymer is not considered 7\%! But since finally optimal water after complete performing experience had been achieved could represent the exact amount of polymer included in the suspension correctly. The results of Tadayonfar et al. are given in Table 2 and Figure 3.

For the soil without polymer existing spaces and dissociation between particles severe reduces its stability, but in the soils with polymer in addition to filling spaces between particles by adhesive polymer material these materials replaced soil particles and since specific density of polymer is less than soil this action cause reducing dry specific weight of soil. By increasing polymer percentage the polymer particles occupy soil particles more and leaded to more reduction of soil specific soil [19]. Observed that yet decreasing specific weight soil is more stable, but should notice to design economy by increasing polymer.

\subsection{Flooding Experiments (ASTM C267)}

Since in practice the resistance of provided samples with polymer to early rains and before initial setting of polymer is very important the critical time of wetting samples should be determined. For this purpose Ferzi et al. produced the samples with $2.5 \mathrm{~cm}$ and height of $12.5 \mathrm{~cm}$ and after different times $0,1,24$ hours, and 30 days remaining in laboratory transmitted in the water to measure stability times of them in the water. According to the given results in Table 3 and Figure 4 and Figure 5 that show the failure procedure of with and without polymer samples maintenance conditions in the laboratory environment during $0,1,24$, and complete dry in flood state it can be said by increasing polymer concentration and drying time the sample stability time in the water is increased.

It could understand from the curve that increasing duration of presenting samples in environment has significant effect on the stability of samples1hr in comparison whit o hr. This mutation for stability duration of samples $24 \mathrm{hr}$ than $1 \mathrm{hr}$ is more considerable. In complete dry case the stability of all polymer samples in the water continued more than 10 days because of perfect setting of polymer. Adhesion behavior was another interested notice that observed in this experiment. After flooding samples failure if the ruptured sample removed from water and dried polymer recycled its adhesion and the sample could stand in the water as before flooding [21]. 
Table 2. Results of protector compaction test (adapted from Tadayonfar et al. [18]).

\begin{tabular}{cccc}
\hline $\begin{array}{c}\text { Maximum dry specific mass } \\
P_{d}\left(\mathrm{gr}_{\mathrm{cm}}\right)\end{array}$ & $\begin{array}{c}\text { Maximum dry specific weight } \\
\gamma_{\mathrm{d}}\left(\mathrm{KN} / \mathrm{m}^{3}\right)\end{array}$ & $\begin{array}{c}\text { Optimal moisture percentage } \\
(\% \omega)\end{array}$ & $\begin{array}{c}\text { The polymer concentration } \\
(\%)\end{array}$ \\
\hline 1.983 & 19.45 & 12.5 & 0 \\
1.980 & 19.42 & 12.4 & 0.5 \\
1.978 & 19.41 & 12.3 & 1 \\
1.972 & 19.35 & 12.3 & 2.5 \\
1.959 & 19.22 & 11.8 & 3 \\
1.952 & 19.15 & 11.5 & 4 \\
\hline
\end{tabular}

Table 3. Results of flooding test (adapted from Farzi et al., [20]).

\begin{tabular}{|c|c|c|c|c|}
\hline Polymer & $0 \mathrm{~h}$ & $1 \mathrm{~h}$ & $24 \mathrm{~h}$ & Dried in oven \\
\hline $0 \%$ & $10 \mathrm{~s}$ & $8 \mathrm{~s}$ & $6 \mathrm{~s}$ & $5 s$ \\
\hline $0.5 \%$ & $19 \mathrm{~s}$ & $290 \mathrm{~s}$ & $2422 \mathrm{~s}$ & $>10 \mathrm{D}$ \\
\hline $1 \%$ & $53.68 \mathrm{~s}$ & $335 \mathrm{~s}$ & $4530 \mathrm{~s}$ & $>10 \mathrm{D}$ \\
\hline $2 \%$ & $235.43 \mathrm{~s}$ & $1740 \mathrm{~s}$ & $10800 \mathrm{~s}$ & $>10 \mathrm{D}$ \\
\hline $2.5 \%$ & $270.73 \mathrm{~s}$ & $2358 \mathrm{~s}$ & $>10 \mathrm{D}$ & $>10 \mathrm{D}$ \\
\hline $3 \%$ & $294.43 \mathrm{~s}$ & $5030 \mathrm{~s}$ & $>10 \mathrm{D}$ & $>10 \mathrm{D}$ \\
\hline $4 \%$ & $460 \mathrm{~s}$ & $5760 \mathrm{~s}$ & $>10 \mathrm{D}$ & $>10 \mathrm{D}$ \\
\hline
\end{tabular}

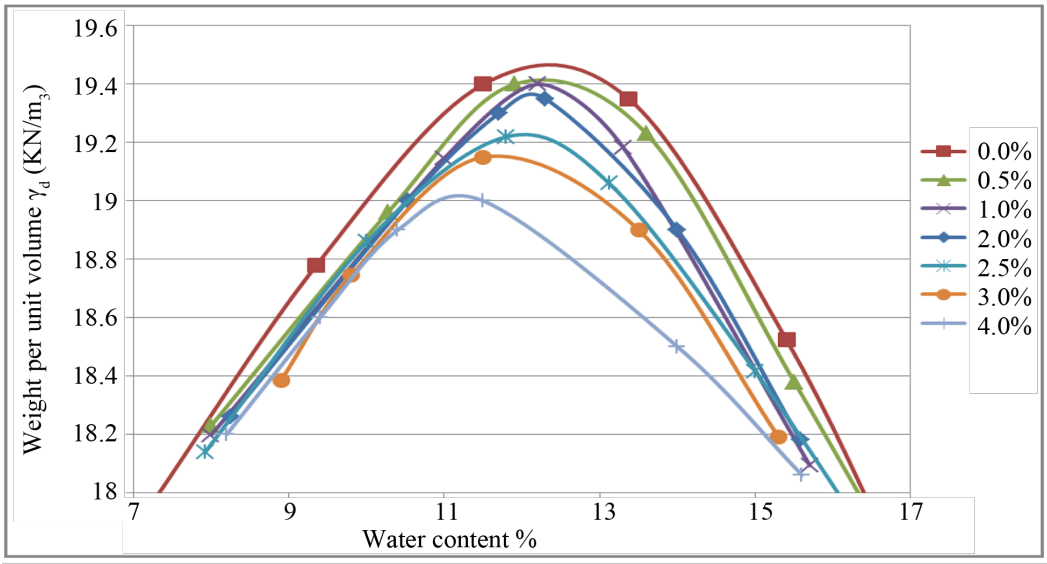

Figure 3. Proctor compaction curve (adapted from Tadayonfar et al., [18]).

\subsection{Wind Resistance Test (ASTM D 3161)}

In this method that designed by Society of Testing and Materials of US panels with 1/7 × 1/3 m had been used. They are exposed to the wind with $97.2 \mathrm{Km} / \mathrm{h}$ speed for 3 hours to specifying loosening or release of the particles. In this study because of limitations of laboratory instruments such as wind tunnel the provided samples in $40 \times 40 \times 3$ dimension are used. The samples according to proctor test are compressed and for 7 days (to ensuring dried samples) are maintained in laboratory environment then transmitted to the wind tunnel for measuring stability times to the wind blowing.

To make samples first specific amount of water (according to percentage of optimal moisture achieved from proctor compaction test) added to polymer suspension. The result solution has been casted in the dry soil to get- 
ting uniform sample after kneading and riling. After 7 days locating in appropriate place had been used in the lab temperature.

Instability procedure of made samples had been tested in the wind tunnel by speed of $20 \mathrm{~m} / \mathrm{s}$. during test the soil particles are separated from each other gradually. The weight was measured and reduced percentage calculated at various times. Results are shown in Table 4 and Figure 6.

According to Table 4 and Figure 6 could conclude that polymer concentration is proportional to wind resistance. This behavior in the samples that located in the environment at least 3 hours (the initial setting time of polymer adherence) caused increasing adherence between particles thus resistance of the samples improved.
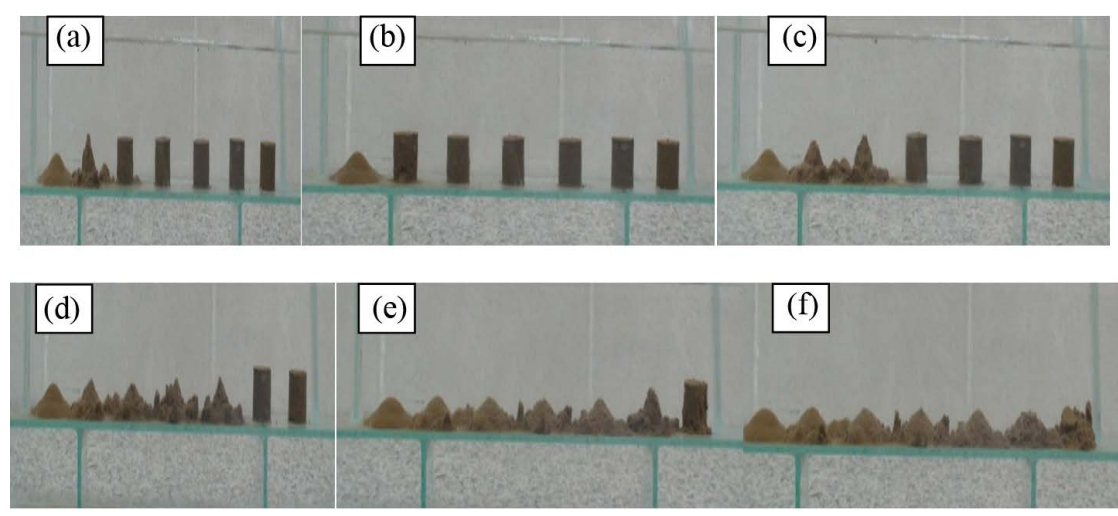

Figure 4. The failure procedure of flooding samples (adapted from Farzi et al. [20]).

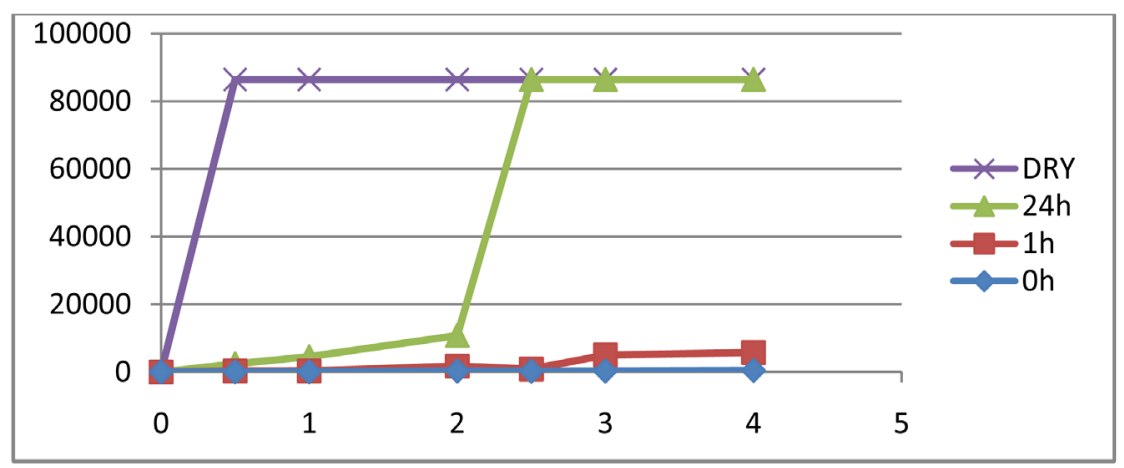

Figure 5. Result of flooding test (adapted from Farzi et al., [19]).

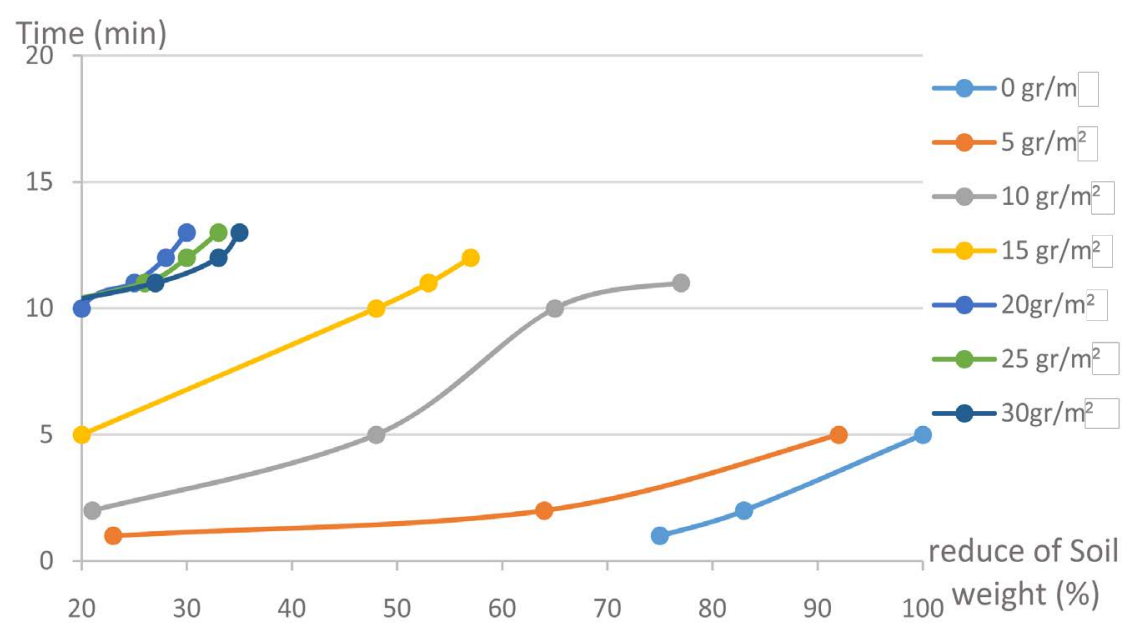

Figure 6. The soil weight reduction curve. 
Table 4. Results of the soil weight reduction (\%).

\begin{tabular}{|c|c|c|c|c|c|c|c|}
\hline Polymer $\left(\mathrm{gr} / \mathrm{m}^{2}\right)$ & $1 \mathrm{~min}$ & $2 \mathrm{~min}$ & $5 \mathrm{~min}$ & $10 \mathrm{~min}$ & $15 \mathrm{~min}$ & $20 \mathrm{~min}$ & $25 \mathrm{~min}$ \\
\hline 0 & $75 \%$ & $83 \%$ & $100 \%$ & - & - & - & - \\
\hline 5 & $23 \%$ & $64 \%$ & $92 \%$ & - & - & - & - \\
\hline 10 & - & $21 \%$ & $48 \%$ & $65 \%$ & $77 \%$ & - & - \\
\hline 15 & - & - & $20 \%$ & $48 \%$ & $53 \%$ & $57 \%$ & - \\
\hline 20 & - & - & $15 \%$ & $20 \%$ & $25 \%$ & $28 \%$ & $30 \%$ \\
\hline 25 & - & - & - & $15 \%$ & $26 \%$ & $30 \%$ & $33 \%$ \\
\hline 30 & - & - & - & $15 \%$ & $27 \%$ & $33 \%$ & $35 \%$ \\
\hline
\end{tabular}

It justified by the relations between resistance parameters of soil and particles adhesion. Soil without polymer showed little resistance. This caused by increasing internal friction angle of soil (more engagement of soil particles to each other) resulted in compressing soil when making samples.

\section{Conclusions}

1) Despite dry specific weight of soil reduction by adding polymer wind resistance of samples increased.

2) By compressing tested soil, with and without polymer, the strength of soil is increased.

3) This idea that adding polymer to soil almost 3 hours after mixing when setting didn't occur and resistance of soil didn't change has no effect isn't correct.

4) Since the wet samples have better wind resistance and remain stable.

5) In general wind resistance of soil increased by increasing polymer concentration.

6) The best value of this polymer for stability against wind can be almost $20-30 \mathrm{gr} / \mathrm{m}^{2}$.

7) It suggested that to optimization operating conditions the test had been done in desert scale and used polymer concentration in natural condition determined by considering others important parameters like temperature, moisture, direction and speed of wind, the vegetation, permeability coefficient of soil, influence of polymer, performance and sprinkle, the density and etc.

\section{Acknowledgements}

Thanks to our cooperator in wind tunnel laboratory for his unsparing assistance at Hakim Sabzevari University.

\section{References}

[1] Bawsher and Kit (1994) Climate of Earth, Extra Tropical Zone. Vol. 2, Bohloul Alijani Translation, SAMT Publications.

[2] McTainsh, G.H. and Pitblado, J.R. (1987) Dust Storms and Related Phenomena Measured from Meteorological Records in Australia.

[3] Azari, F. (1984) Codes and Monitoring Methods, Atmospheric Sciences and Meteorology Center for Higher Education. Publications of Meteorological Organization.

[4] Shahsavani (2010) Effects on Dust Storms on the Health an Environment. Journal of Science and Medicine University of North Khorasan, 2, 45-56.

[5] Reheis, M. (1997) Dust Deposition of Ovens (Dry) Lake, 1991-1994: Preliminary Finding. Journal of Geophysical Research, 102, 25999-26008. http://dx.doi.org/10.1029/97JD01967

[6] Vine, H. (1987) Wind-Blown Materials and W. African Soils: An Explanation of the Ferrallitic Soil over Loose Sandy Sediments Profile. Geological Society Special Publication, 35, 171-183. http://dx.doi.org/10.1144/GSL.SP.1987.035.01.12

[7] Walker, P.H. and Costing, A.B. (1971) Atmospheric Dust Accession in South-Eastern Australia. Australian Journal of Soil Research, 9, 1-5. http://dx.doi.org/10.1071/SR9710001

[8] Alijani, B. (2000) Climate of Iran. Publication of Payamnour University.

[9] Alijani, B. (1987) Diversity Relation Silica Path with Air Systems. Geographical Journal, 4. 
[10] Ameri, M. (2005) Stability Guidelines Embankment and Pavement Layers of Roads. Education, Research and Technology Assistance of Iran University of Science and Technology, Institute of Transportation.

[11] Okhovat, N. and Pourhoseini, R. (2000) Improving Resistance Behavior of Soil with Synthetic Fibers. 5th National Congress of Civil Engineering.

[12] Dashti, N. and Safikhani, A. (2008) Investigation of Experimental Results of Using Slag in Embankment.

[13] Naderi, H. (2009) Effect of Blast Furnace Granulated Slag of Zobahan od Isfahan on the Resistance and Inflammatory Features of the Clay Stabilized by Lime Adjacent Soulphat. Master Thesis, Bu-Ali Sina University of Hamedan.

[14] Hoover, J.M. (1987) Dust Control on Construction Sites. Arizona Department of Transportation, Report No. FHWAAZ, 86-807, $65 \mathrm{p}$.

[15] Alaie, H. (2009) Study of Stabilized Soil Features with Polymer Material. Master Thesis, Islamic Azad University Najafabad Branch.

[16] Masoumi, A. and Abtahi, H. (2009) Using New Chemical Material to Stabilization of Loose Sandy Soils. 1st National Chemical Congress of Iran.

[17] Samaie, H.R., Golchin, A. and Mosadeghi, M.R. (2006) Controlling Pollution Due Wind Erosion by Solution Polymers in Water. Congress of Soil and Environment and Sustainable Development.

[18] Tadayonfar, Gh. and Tadayonfar, V. (2014) Improving Mechanics Properties of Silt Soils Using Poly Vinyl Acetate. 2nd Internal Conference in Geotechnical Engineering.

[19] Palmer, J.T., Edgar, T.V. and Boresi, A.P. (1995) Strength and Density Modification of Unpaved Road Soils Due to Chemical Additives. Master's Thesis, University of Wyoming, Department of Civil and Architectural Engineering, Laramie, Wyoming, January, 33-41.

[20] Farzi, Gh. and Reza Tadayonfar, Gh. (2012) Improving Mechanics Properties of Silt Soils Using Emulsion Polymers. Research Design, Hakim Sabzevari University.

[21] Farzi, Gh. and Reza Tadayonfar, Gh. (2012) Improving Mechanics Properties of Silt Soils Using Base Water Polymers. Research Design, Hakim Sabzevari University. 